\title{
The movement of funds on the residents' accounts in Russia
}

\author{
S.M. Borodachev \\ Institute of Economics and Management, Ural Federal University named after the first President of Russia B. N. \\ Yeltsin, Mira St 19, 620002, Ekaterinburg, Russia. \\ e-mail: s.m.borodachev@gmail.com
}

\begin{abstract}
The work proposes a model of funds formation in current and fixed-term (ruble and currency) accounts and transfers of funds between them. The sources of money are loans issued by commercial banks, placement of government domestic debt, the positive balance of foreign trade. The financial parameters and characteristics of the system are estimated using the Kalman filter. The adequacy of the model is confirmed by simulation modeling. It was found that the rate of creation of rubles in current accounts increased from $\approx 8 \%$ per annum in $2015-16 \approx$ to $12 \%$ in $2017-18$ and to $29 \%$ in $2019-20$. The leakage of foreign currency from accounts (in addition to the official outflow of capital) was $\approx 12,50,35$ billion dollars per annum during the same periods.
\end{abstract}

Keywords: government debt, escape of capital, money creation, Kalman filter, simulation

\section{INTRODUCTION}

The aim of this work is to reveal the mechanisms for changing funds in current and savings (fixed-term) accounts of residents in the banking system of Russia. Provide an estimation of the key parameters that characterize the financial system of Russia and estimate cash flows between types of accounts. Track trends in this area.

\section{MODEL AND DATA}

To identify the relationships and build a model, we will study the correlations of quantities that seem to be related to the processes under study. $t=0,1, \ldots, T$ - moments of the beginning of successive months over the last 6 years. Data from the website of the Central Bank of Russia [1]. "Review of Credit Institutions": $c u^{t}$ - transferable deposits (current accounts) in rubles, trillion P, $s a 1^{t}-$ other deposits (savings fixed-term accounts) in rubles, trillion P, $s a 2^{t}-$ other deposits (savings fixed-term accounts) in foreign currency, trillion P, placed in the banking system by residents of the Russian Federation. "Foreign trade in goods (according to the balance of payments methodology)": st $\$^{t}$ - trade balance in a month from $t$ to $t+1$, billion $\$$. "Financial operations of the private sector": of $\$$ t - capital outflow for the previous month, billion \$. RES\$ $\$^{t}$ - "International Reserve Assets of the Russian Federation" billion \$. $S^{t}$ - "Ruble exchange rate" (RUB/USD) at time $t$.

Data from the website of the Ministry of Finance of Russia [2]. "The volume of the government domestic debt of the Russian Federation": $g d^{t}$ at time $t$, "The volume of redeemed government debt": $g d r^{t}$ in a month from $t$ to $t+1$ (negative values), trillion P. According to these data, it is possible to calculate the amount of placed debt in month by calculation. 
$g d d^{t}=g d^{t+1}-g d^{t}-g d r^{t}$. See fig. 1 .

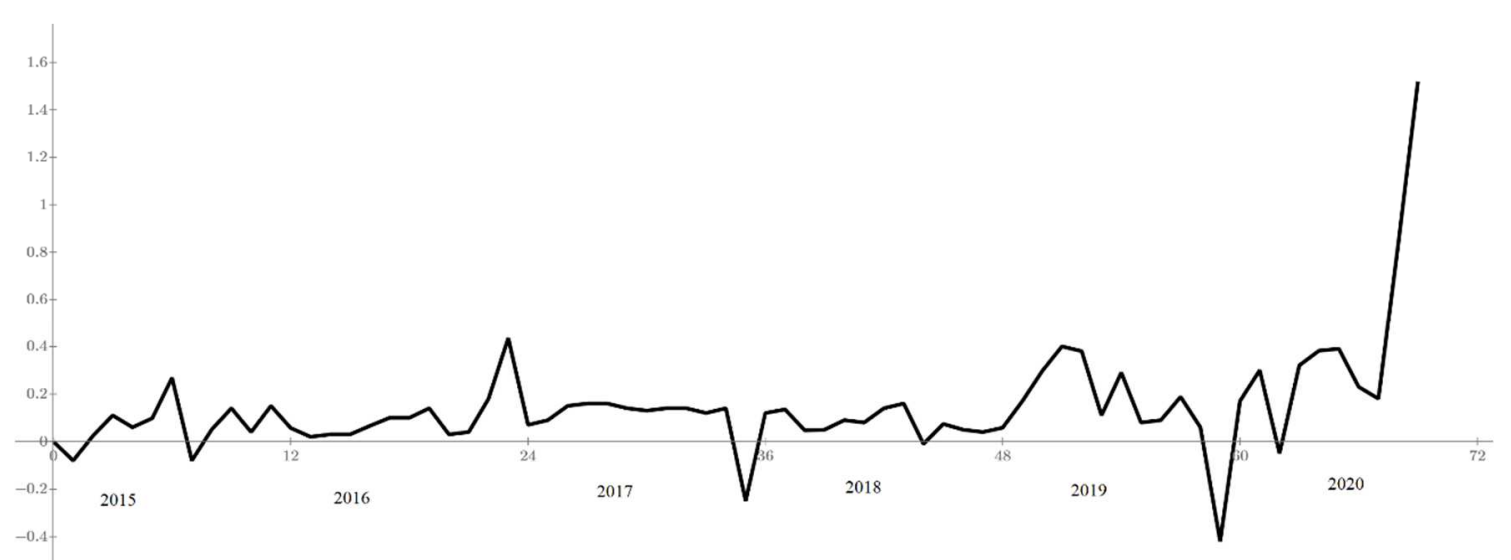

Figure 1. The placements of the Russian government debt. Monthly data from 01.01.2015 to 01.11.2020 trillion P.

Estimation of the correlation matrix from data $\Delta c u^{t} \Delta s a 1^{t} \Delta s a 2 \$^{t} g d d^{t} g d r^{t} g d^{t} s t \$^{t}$ of $\$^{t+1} \Delta R E S \$^{t} \Delta S^{t}$, where $\Delta c u^{t}=c u^{t+1}-c u^{t}$, the rest $\Delta$ is similar, is given below.

\begin{tabular}{|l|l|l|l|l|l|l|l|l|l|l|}
\hline & $\Delta c u^{t}$ & $\Delta s a 1^{t}$ & $\Delta s a 2 \$^{t}$ & $g d d^{t}$ & $g d r^{t}$ & $g d^{t}$ & $s t \$^{t}$ & $o f \$^{t+1}$ & $\Delta R E S \$^{t}$ & $\Delta S^{t}$ \\
\hline$\Delta c u^{t}$ & 1,00 & 0,51 & $-0,20$ & $-0,14$ & 0,13 & 0,29 & 0,01 & $-0,20$ & $-0,01$ & 0,10 \\
\hline$\Delta s a 1^{t}$ & 0,51 & 1,00 & $-0,25$ & $-0,27$ & 0,04 & $-0,04$ & 0,23 & 0,09 & $-0,05$ & $-0,01$ \\
\hline$\Delta s a 2 \$^{t}$ & $-0,20$ & $-0,25$ & 1,00 & $-0,15$ & $-0,06$ & $-0,10$ & 0,17 & 0,20 & 0,24 & $-0,12$ \\
\hline$g d d^{t}$ & $-0,14$ & $-0,27$ & $-0,15$ & 1,00 & $-0,01$ & 0,19 & $-0,20$ & 0,04 & $-0,02$ & $-0,01$ \\
\hline$g d r^{t}$ & 0,13 & 0,04 & $-0,06$ & $-0,01$ & 1,00 & $-0,08$ & 0,00 & 0,03 & $-0,14$ & $-0,07$ \\
\hline$g d^{t}$ & 0,29 & $-0,04$ & $-0,10$ & 0,19 & $-0,08$ & 1,00 & 0,21 & $-0,03$ & 0,33 & 0,02 \\
\hline$s t \$^{t}$ & 0,01 & 0,23 & 0,17 & $-0,20$ & 0,00 & 0,21 & 1,00 & 0,50 & 0,02 & 0,05 \\
\hline of $\$^{t+1}$ & $-0,20$ & 0,09 & 0,20 & 0,04 & 0,03 & $-0,03$ & 0,50 & 1,00 & $-0,32$ & $-0,18$ \\
\hline$\Delta R E S \$^{t}$ & $-0,01$ & $-0,05$ & 0,24 & $-0,02$ & $-0,14$ & 0,33 & 0,02 & $-0,32$ & 1,00 & $-0,11$ \\
\hline$\Delta S^{t}$ & 0,10 & $-0,01$ & $-0,12$ & $-0,01$ & $-0,07$ & 0,02 & 0,05 & $-0,18$ & $-0,11$ & 1,00 \\
\hline & 0.48 & 0.48 & 0.32 & 0.22 & 0.06 & 0.41 & 0.44 & 0.51 & 0.4 & 0.12 \\
\hline
\end{tabular}

The Wilkes-Bartlett criterion rejects the hypothesis of pairwise independence of all components with $s l=10^{-9}$.

The last row contains estimates of the multiple correlation coefficient of each component with all others (= coefficients of determination in regression analysis). We can note a weak correlation of changes in all indicators with changes in the dollar exchange rate. Determination of capital outflow: strong positive correlation with the trade balance and negative with the replenishment of reserve assets. Changes in ruble accounts are positively correlated with changes in ruble deposits and the size of government debt. Changes in ruble deposits are negatively correlated with the placements of government debt.

After several attempts to select explanatory variables, the following model of the studied financial subsystem was chosen. Basic assumptions. Current deposits are constantly growing due to the issuance of loans by commercial banks ahead of their return (creation of money according to the pyramid scheme), government injections (in particular, from the new domestic debt) and other income. Part of the current deposits goes into term deposits. The positive balance of foreign 
trade replenishes time deposits in rubles and foreign currency and determines the export of capital abroad. Let's recalculate the Central Bank data in $\$$ in $\mathrm{P}$ at the rate $S^{t}: o f^{t}$ - capital outflow for the previous month, $s t^{t}-$ trade balance in the month from $t$ to $t+1$, trillion P. System dynamics:

$$
\begin{aligned}
& c u 0^{t+1}=\left(1+\frac{\beta_{0}}{1200}\right) c u 0^{t}-c u s a 1^{t}+\frac{10}{1200} g d^{t}+\delta_{0}^{t}, \\
& s a 10^{t+1}=s a 10^{t}+c u s a 1^{t}+s t s a 1^{t}-\beta_{2} g d d^{t}+\delta_{1}^{t}, \\
& s a 20^{t+1}=\frac{S^{t+1}}{S^{t}}\left(1-\frac{\beta_{1}}{1200}\right) s a 20^{t}+s t s a 2^{t}+\delta_{2}^{t}, \\
& \text { of } 0^{t+1}=-s t s a 1^{t}-s t s a 2^{t}+\beta_{3} s t^{t}+\delta_{3}^{t}, \\
& \text { cusa } 1^{t+1}=c u s a 1^{t}+\delta_{4}^{t}, \\
& s t s a 1^{t+1}=s t s a 1^{t}+\delta_{5}^{t}, \\
& s t s a 2^{t+1}=s t s a 2^{t}+\delta_{6}^{t} .
\end{aligned}
$$

Variables with 0 at the end indicate the true values of the corresponding observables. The first term on the right side of (1) means the exponential growth of current deposits at a rate of $\beta_{0} \%$ per annum. cusal ${ }^{t}-$ transfer of money from current accounts to fixed-term ruble ones for a month from the moment t. stsa $1^{t}$, stsa $2^{t}-$ similarly, the transfer of money from the balance of trade to fixed-term ruble and currency accounts. The third term on the right side of (1) means approximately $10 \%$ government debt yield. The fourth term on the right-hand side of (2) means that the placed public debt is bought (in a share $\beta_{2}$ ) from fixed-term ruble accounts. The first coefficient on the right-hand side (3) provides the conversion into rubles of foreign currency deposits (exponentially decreasing at a rate of $\beta_{1} \%$ per annum) rolling over from the previous month. The third term in (4) shows the amount of funds (as a share $\beta_{3}$ of the foreign trade balance) going to replenish deposits (in rubles and foreign currency) and for the official export of capital abroad of ${ }^{t}$. (5), (6), (7) - cash flows that change over time.

The left-hand sides (1) - (7) constitute the state vector of the system $x^{t+1}$, the control vector

$$
u^{t}=\left(\begin{array}{lll}
g d d^{t} & g d^{t} \quad s t^{t}
\end{array}\right)^{T}
$$

the observed output quantity $y^{t}=\left(\begin{array}{llll}c u^{t} & s a 1^{t} & s a 2^{t} & o f^{t}\end{array}\right)^{T}$, then the model of the system in the state space has the standard form

$$
\begin{aligned}
& x^{t+1}=F^{t} x^{t}+G^{t} u^{t}+w^{t}, \\
& y^{t}=H^{t} x^{t}+v^{t},
\end{aligned}
$$

where the operator of evolution $F^{t}$, control $G^{t}$, and observation $H^{t}, w^{t}, v^{t}-$ is the system and observation noises. Monthly data from 01.01.2015 to $01.10 .2020(t=0, \ldots, 69=T)$ see table 1 .

\begin{tabular}{|l|l|l|l|l|l|l|l|}
\hline \multicolumn{2}{|l|}{ Table 1. Data for calculations } \\
\hline$t$ & 0 & 1 & 2 & 3 & $\ldots$ & 68 & 69 \\
\hline$c u^{t}$ & 8.12 & 8.21 & 8.19 & 8.16 & $\ldots$ & 17.04 & 17.43 \\
\hline$s a 1^{t}$ & 16.27 & 16.07 & 16.3 & 16.28 & $\ldots$ & 26.26 & 26.5 \\
\hline$s a 2^{t}$ & 10.83 & 13.63 & 12.15 & 11.64 & $\ldots$ & 15.51 & 16.41 \\
\hline
\end{tabular}




\begin{tabular}{|l|l|l|l|l|l|l|l|}
\hline$o f^{t}$ & 2.02 & 0.797 & 1.1 & 0.215 & $\ldots$ & -0.007 & 0.311 \\
\hline$g d d^{t}$ & 0 & -0.08 & 0.024 & 0.11 & $\ldots$ & 0.831 & 1.52 \\
\hline$g d^{t}$ & 7.24 & 7.24 & 7.16 & 6.99 & & 11.58 & 12.4 \\
\hline$s t^{t}$ & 0.933 & 0.978 & 0.978 & 0.845 & $\ldots$ & 0.765 & 0.513 \\
\hline$S^{t}$ & 59.233 & 69.939 & 61.781 & 58.062 & $\ldots$ & 74.638 & 79.685 \\
\hline
\end{tabular}

\section{KALMAN FILTER AND INTERPRETATION OF CALCULATION RESULTS}

The Kalman filter is widely used in economic research (see, for example, [3,4]). It makes it possible to estimate the parameters of the system, estimate and predict the characteristics of the system's state and output.

Model parameters

$$
\theta=\left(\sigma v_{0} \sigma \delta \sigma_{P} \beta\right)^{T},
$$

where $\sigma \delta$ - is the vector of standard deviations of errors in (1) - (7). The covariance matrices of vectors $w^{t}, v^{t}$ are considered to be diagonal, the latter being proportional $\sigma v_{0}{ }^{2}$. We choose the first components of the initial state estimate $\hat{x}^{T l-1 \mid T l-1}$ equal to the corresponding observed values, the last three were selected according to the best description, and the covariance matrix of this estimate $\sigma_{P}^{2} I, I-$ is the identity matrix.

The estimation of the vector of the model parameters was carried out by the method of minimizing the RMS sum of the prediction errors of the output vector in the fitting window ( $T l$ is the initial moment, $T u$ is the final moment of the window).

$$
\begin{gathered}
R M S E(\theta)=\sqrt{\frac{1}{T u-(T l-1)} \sum_{t=T l}^{T_{u}}\left\|y^{t}-\hat{y}^{t \mid t-1}\right\|^{2}}, \\
\hat{\theta}_{R M S E}=\underset{\hat{\theta}}{\arg \min } \operatorname{RMSE}(\hat{\theta}) .
\end{gathered}
$$

Here $\hat{y}^{t t-1}-$ is a forecast based on information at the moment $t$ - 1 (i.e., up to the value of $y^{t-1}$ and $u^{t-1}$ ) of the output vector at the next moment. Calculations were carried out at PTC® MathcadPrime®.

First, let us choose a fitting window within a relatively quiet (without political cataclysms) period from 06.01.2016 to $11.01 .2019(t=17, \ldots, 58)$. Estimated parameters (11) $\beta_{0}=11.97$ - with such a percentage per annum current accounts grow for reasons other than income from government domestic debt and transitions from / to term deposits. $\beta_{1}=24.67-$ foreign currency deposits are decreasing at such an annual rate (about $\$ 50$ billion per year), apparently flowing abroad in addition to the export of capital of ${ }^{t}$. This leakage, however, is constantly compensated by incomes from foreign trade. $\beta_{2}=0.48-$ almost half of the placed government debt is bought from the residents' fixed-term ruble accounts, $\beta_{3}=0.76$ - is the share foreign trade balance goes to deposits (in rubles and foreign currency) and is officially exported abroad, the rest goes to replenish the reserve assets of the Russian Federation, etc.

For estimates of the transfer of money between accounts and replenishment of accounts from trading, see fig. 2. 


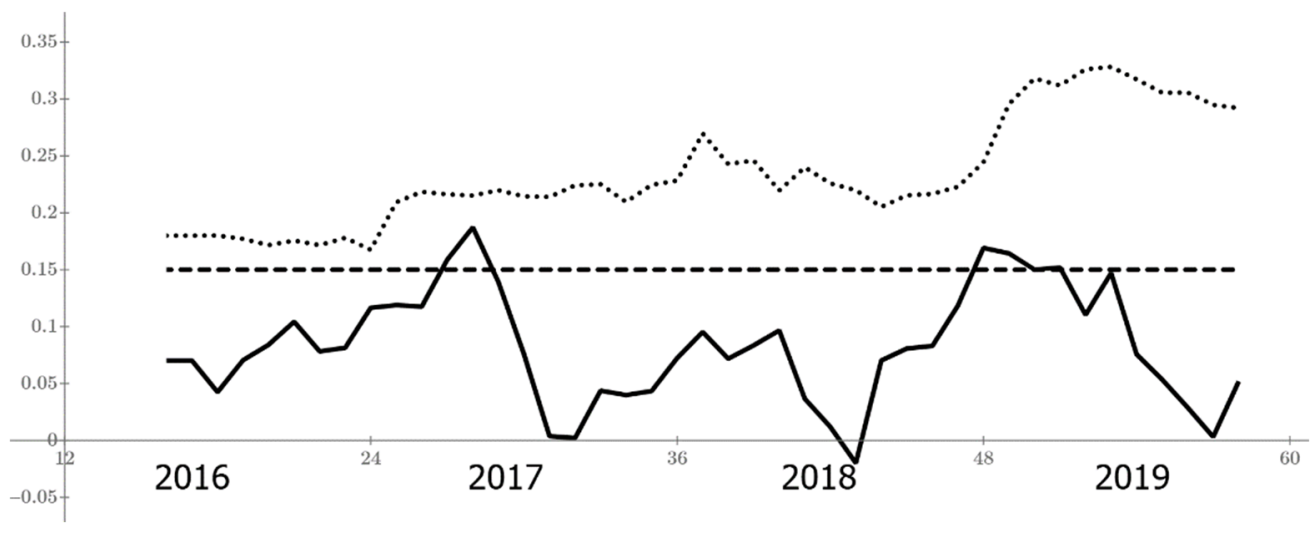

Figure 2. Estimates of the money transfer for a month from the moment t. cus $a 1^{t}-$ from current accounts to fixed-term ruble deposits (solid curve), stsa ${ }^{t}$ - from the balance of trade on ruble deposits (dashed curve), stsa $2^{t}$ - from the balance of trade on foreign currency deposits (dotted curve). Trillion P.

There are noticeable slowdowns in the transitions from current accounts to ruble deposits (and even reverse transitions) in the summer and autumn periods, which may be associated with periods of vacations. Incomes from trading in ruble deposits are practically unchanged; in foreign currency deposits they have grown sharply in 2019.

Achieved $R M S E=0.533$ trillion P. For a random walk model (when the forecast is the previous value) $R M S E R W=$ 0.705 trillion P.

In the period $2015-$ mid-2016 $(t=1, \ldots, 17)$ estimate of vector $\beta=(7.926 .010 .320 .87)^{\mathrm{T}}$. Current accounts grew more slowly, foreign currency deposits flowed out more slowly (about $\$ 12$ billion a year in addition to the official export of capital). The government debt was bought to a lesser extent from the residents' fixed-term ruble accounts, and a smaller part of the income from trade went to other purposes. In the period end-of-2019 $-2020(t=58, \ldots, 69)$ estimate of vector $\beta=(29.3617 .720 .850 .77)^{\mathrm{T}}$. The rapid growth of current accounts, currency outflow from accounts of about $\$ 35.4$ billion a year - this is less than in the previous two years. An increasing part of government debt is bought by residents.

\section{SIMULATION}

The issues of the significance of estimates and the adequacy of the model when using the Kalman filter are not as simple as, for example, in regression analysis. In particular, since the filter forecast relies heavily on the known previous output, it will always be good, even with an unsuccessful model. To check the adequacy, it is logical to simulate the functioning of the system with the estimated parameters, in comparison with real behavior. For this, we use the equations of dynamics (9) и (10) without noise elements, where the estimates of parameters $\beta$ are substituted into the evolution and control operators. We start from the corresponding initial state vector, the last 3 components of which (transfers) are chosen equal to some averages of the values estimated above (and are constant). Controls - real ones (8). We will do this for a quiet time interval (see fig. 3). Initial state vector (8.96 18.79 13.940 .110 .0830 .150 .246$)^{\mathrm{T}}$. 

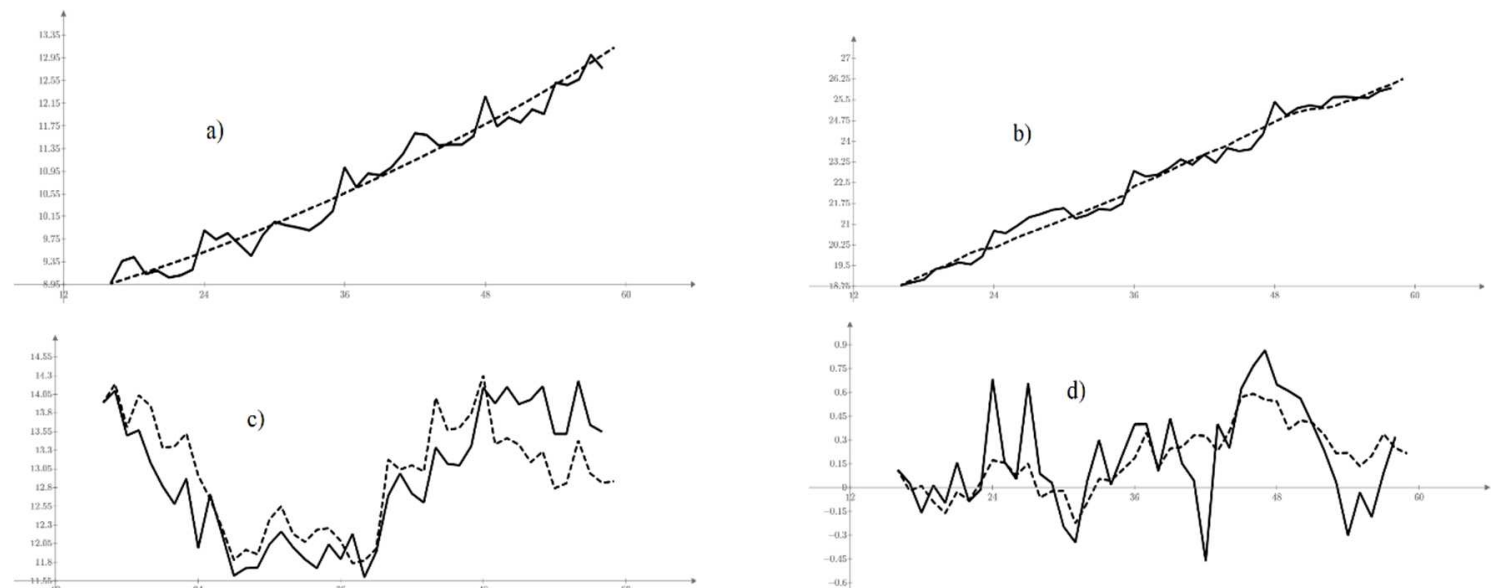

Figure 3. Comparison of real (solid curves) and simulated (dotted curves) financial indicators from 01.06.2016 to 01.11.2019 ( $t$ $=17, \ldots, 58)$. a) - current accounts, b) - ruble deposits, c) - foreign currency deposits, d) - export of capital. In trillion $\mathrm{P}$.

The good coincidence (in overall) of the curves in fig. 3 allows us to make a conclusion about the adequacy of the proposed model to the real system. The discrepancy in foreign currency deposits can be explained by an increase in the transition of trade income to foreign currency deposits (see fig. 2), which was not taken into account in the simulation. Individual peak discrepancies are associated with fluctuations in exchange rates, foreign exchange interventions by the Central Bank and replenishments of international reserve assets of the Russian Federation.

\section{CONCLUSION}

In the previous work [4], devoted to cross-border transfers of money, an estimate was obtained for the monthly creation of ruble deposits (current and term together) by Russian Federation commercial banks of about 300 billion P. This is consistent with the results of this work: on average $20 \%$ per year creation of current deposits (which gives $\approx 200$ billion P per month) plus transfer from current accounts to fixed-term ruble accounts $\approx 100$ billion P per month (see Fig. 2). In general, the work identifies the main reasons, mechanisms and parameters of the movement of funds on various types of accounts of residents in the banking system of the Russian Federation.

\section{REFERENCES}

1. https://www.cbr.ru/statistics/

2. https://minfin.gov.ru/ru/perfomance/public_debt/internal/structure/total/

3. S. M. Borodachev, Physics - Economics interdisciplinary analogies in modelling of Russian financial system. CEUR Workshop Proceedings. v. 2562, p. 113-120, 2020.

4. S. M. Borodachev, Toward the modeling of Russia's monetary system. Preprints (www.preprints.org), doi:10.20944/preprints202003.0086.v1, 2020. 